University of Nebraska - Lincoln

DigitalCommons@University of Nebraska - Lincoln

Nebraska Cooperative Fish \& Wildlife Research Nebraska Cooperative Fish \& Wildlife Research Unit -- Staff Publications

2012

\title{
Habitat selection by adult walleye during spawning season in irrigation reservoirs: A patch occupancy modeling approach
}

\author{
Dustin R. Martin \\ University of Nebraska-Lincoln, dustin.martin@huskers.unl.edu \\ Larkin A. Powell \\ University of Nebraska-Lincoln, Ipowell3@unl.edu \\ Kevin L. Pope \\ U.S. Geological Survey-Nebraska Cooperative Fish and Wildlife Research Unit, kpope2@unl.edu
}

Follow this and additional works at: https://digitalcommons.unl.edu/ncfwrustaff

Part of the Other Environmental Sciences Commons

Martin, Dustin R.; Powell, Larkin A.; and Pope, Kevin L., "Habitat selection by adult walleye during spawning season in irrigation reservoirs: A patch occupancy modeling approach" (2012). Nebraska Cooperative Fish \& Wildlife Research Unit -- Staff Publications. 100.

https://digitalcommons.unl.edu/ncfwrustaff/100

This Article is brought to you for free and open access by the Nebraska Cooperative Fish \& Wildlife Research Unit at DigitalCommons@University of Nebraska - Lincoln. It has been accepted for inclusion in Nebraska Cooperative Fish \& Wildlife Research Unit -- Staff Publications by an authorized administrator of DigitalCommons@University of Nebraska - Lincoln. 


\title{
Habitat selection by adult walleye during spawning season in irrigation reservoirs: a patch occupancy modeling approach
}

\author{
Dustin R. Martin • Larkin A. Powell • \\ Kevin L. Pope
}

Received: 25 January 2011 / Accepted: 27 October 2011/Published online: 6 November 2011

(C) Springer Science+Business Media B.V. 2011

\begin{abstract}
Recruitment of walleye (Sander vitreus Mitchill) is limited in irrigation reservoirs of the Republican River basin in southwestern Nebraska. The causal mechanism for this limited recruitment is unknown, but may be related to a lack of suitable spawning habitat. Patch occupancy models were developed to describe variation in detection probability and habitat selection during spawning season using shoreline electrofishing data. Detection of adult walleye was negatively affected by water temperature, silt substrate, and woody cover. Adult walleye selected sites with cooler water temperatures and greater fetch at Enders Reservoir, and large rock substrate and no cover at Hugh Butler Lake; these
\end{abstract}

D. R. Martin $(\bowtie)$

Nebraska Cooperative Fish and Wildlife Research Unit, and School of Natural Resources, University of Nebraska, 013 Hardin Hall, 3310 Holdrege Street,

Lincoln, NE 68583, USA

e-mail: dustin.martin@huskers.unl.edu

L. A. Powell

School of Natural Resources, University of Nebraska, 419 Hardin Hall, 3310 Holdrege Street, Lincoln, NE 68583, USA

K. L. Pope

U.S. Geological Survey-Nebraska Cooperative Fish and Wildlife Research Unit, and School of Natural Resources, University of Nebraska, 424 Hardin Hall, 3310 Holdrege Street, Lincoln, NE 68583, USA characteristics are limited to areas on or near the riprap dams in both reservoirs. Walleye eggs were also only found in these areas. We conclude that patch occupancy modeling provided valuable information when considering habitat improvement projects and propose a management approach for the addition of walleye spawning habitat in irrigation reservoirs.

Keywords Sander vitreus - Detection probability . Occupancy probability . Habitat improvement

\section{Introduction}

Adult fish select spawning sites to maximize hatching and survival rates of progeny. Substrate type, depth, dissolved oxygen, and temperature are commonly cited as critical spawning habitat characteristics for fish (McMahon et al. 1984; Gipson and Hubert 1993; Gosch et al. 2006), though characteristics of spawning habitat vary widely among species. Walleye (Sander vitreus Mitchill) spawn in many different habitats: tributaries entering lakes (Pflieger 1997); coarse substrate and shallow depths in tributaries of large lakes (Kelder and Farrell 2009; Chalupnicki et al. 2010); flooded marshes (Priegel 1970); upper riverine portions of reservoirs (Quist et al. 2004); small patches of gravel located within larger sandy shores (Johnson 1961); gravelly, sandy, or stony shallow shoals within lakes (Scott 1967); rocky wave-washed shoreline in lakes with no inlet streams (Becker 
1983); and riprap on the face of reservoir dams (Grinstead 1971). Conditions at these habitats likely increase progeny survival rates by maximizing dissolved oxygen and minimizing siltation on eggs during the 10-14 day hatching period (Johnson 1961; McMahon et al. 1984).

Spawning site selection by adult fish is constrained by the availability of habitats. Large variations of water levels in irrigation reservoirs of the midwestern United States of America cause available habitat to vary within and among years. During periods of low water, recruitment of fishes may be limited due to the lack of suitable spawning habitat and increased predation from crowding. This variation can negatively affect year-class strength of walleye in reservoirs (Groen and Schroeder 1978).

Traditional habitat selection methods (e.g., logistic regression and multivariate analysis of variance) may misrepresent actual habitat selection by failing to account for the probability of detection given the sampling method (Gu and Swihart 2004). Habitat variables positively related to this detection probability may be over-emphasized in traditional habitat selection modeling. Detection probability is generally $<$ 1.0 and increases with repeated sampling of the same sites (e.g., the detection probability of small mammals in traps increased from 0.25 to 0.77 when the sampling intensity was increased from 1 to $5[\mathrm{Gu}$ and Swihart 2004]). Estimates of habitat use may be biased when not accounting for detection probability (Tyre et al. 2003). Patch occupancy modeling is a technique for estimating site occupancy that explicitly accounts for detection probability (MacKenzie et al. 2002). Unfortunately, to our knowledge only two studies to date (Burdick et al. 2008; Hayer and Irwin 2008) have been published in the fishery literature using this method.

The ability to distinguish between habitat variables associated with increased detection of fish and those associated with increased occupancy of target fish is important for habitat selection studies. Most previous habitat improvements (e.g., adding spawning substrate) have been based on traditional habitat selection studies that did not account for detection probability. Therefore, patch occupancy modeling should allow resources for habitat improvement to be better utilized.

Our objective was to examine habitat selection by adult walleye during spawning season using patch occupancy modeling. We used an a priori research hypothesis (based on previous knowledge of these systems and literature) that adult walleye select spawning sites with coarser substrate and large maximum fetch (i.e., water surface area available for wind to act upon before hitting a site). Previous research has indicated that walleye select sites with coarser substrates (Scott 1967; Grinstead 1971) to decrease the risk of siltation on eggs during the 10-14 day hatch period and walleye select sites with greater fetch (Becker 1983) to increase water flow (i.e., increase oxygen flow) over eggs. In order to account for variability in catchability of adult walleye, we also included other variables (e.g., temperature, conductivity, cover, etc.) to create models accounting for both detection and occupancy.

\section{Study area}

Two irrigation reservoirs with historically variable walleye year-class strength in southwestern Nebraska were chosen as study sites. Long-term standard sampling by the Nebraska Game and Parks Commission documented that natural recruitment of walleye is highly variable in these reservoirs. Therefore, walleye are stocked annually into these reservoirs to sustain viable populations.

Enders Reservoir, located in Chase County, Nebraska, is an irrigation reservoir that was constructed along Frenchmen Creek by the U.S. Bureau of Reclamation in 1951. At conservation-pool (i.e., the highest non-flood, water-storage level), Enders Reservoir is characterized by a water level of $948.5 \mathrm{~m}$ above mean sea level, surface area of 485 ha and maximum depth of $18.3 \mathrm{~m}$. The shoreline of Enders Reservoir is mostly composed of silt/sand substrate with small cottonwood (Populus deltoides Bartram) trees lining the shoreline. Areas of large rock substrate are restricted to the downstream portion of the reservoir with the majority being on or near the large, riprap dam (Fig. 1). A few areas of large rock substrate have been added on the eastern shore during past aquatic rehabilitation projects.

Hugh Butler Lake (Red Willow reservoir), located in Frontier County, Nebraska, is an irrigation reservoir that was constructed along Red Willow Creek by the U.S. Bureau of Reclamation in 1962. At conservation pool, Hugh Butler Lake is characterized by a water level of $786.9 \mathrm{~m}$ above mean sea level, surface area of 660 ha, and maximum depth of $15.2 \mathrm{~m}$. Hugh Butler 


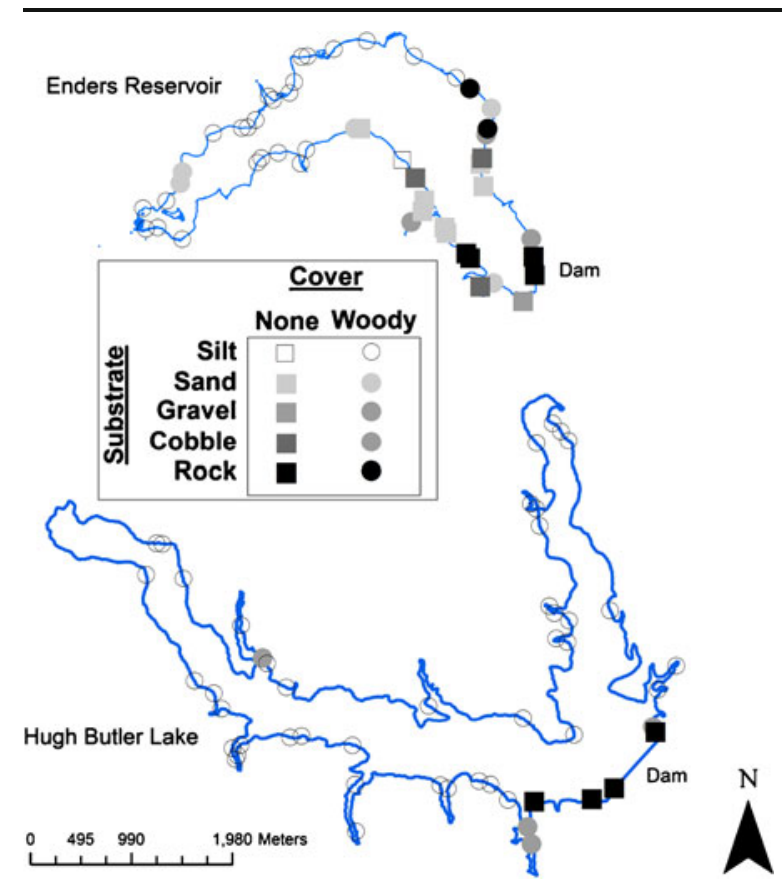

Fig. 1 Spatial distribution of shoreline substrate and cover type during spring 2008 at Enders Reservoir, Nebraska and Hugh Butler Lake, Nebraska

Lake has two inflow sources creating a reservoir with two arms: Spring Creek to the north and Red Willow Creek to the west. The shoreline of Hugh Butler Lake is mostly composed of silt substrate with small cottonwood trees lining the shoreline. Areas of large rock substrate are restricted to the large, riprap dam and small jetties at boat ramps for angler access (Fig. 1).

Both reservoirs are located within the Republican River basin in southwestern Nebraska and the watersheds are dominated by rolling grasslands and irrigated cropland. The Republican River basin has been the source of much controversy over water allocations between the three states within the basin: Colorado, Nebraska, and Kansas. Thus, water withdrawals for irrigation are quite variable among years and reservoirs within the basin.

Drought conditions have dominated southwestern Nebraska for the past decade and have limited the amount of water available for irrigation withdrawals. Low water levels have allowed small trees to become established along the shoreline of both reservoirs. However, rainfall during the springs of 2007 and 2008 caused an increase in water levels that altered available habitat for spawning fishes from a simple habitat of mostly barren substrate to a more complex habitat of flooded trees. Changes in littoral habitat also altered our efficiency of sampling walleye by flooding trees and preventing access to shallow water habitat preferred by walleye; thus necessitating an approach that accounts for differences in catchability among sites within a reservoir.

\section{Materials and methods}

Adult fish

Fifty sampling sites (minimum 60-m apart) were randomly selected without stratification for each reservoir using shoreline layers created from bathymetric maps of each reservoir (Lake Mapping Program of the Nebraska Game and Parks Commission) in ArcMap 9.3. A pulsed-DC boat-mounted electrofisher (Reynolds 1996) was used to sample these 50 sites at each reservoir. Sampling for adult walleye occurred at night during spring when water temperature was $7-10^{\circ} \mathrm{C}$. Adult walleye were assumed to be on spawning sites during this time because male walleye typically spend extended periods on spawning grounds during pre-spawn and spawn (Pflieger 1997; Schoenebeck and Hansen 2005), and acousticallytagged walleye also migrated to the dam at this time (Martin 2008).

Each site was sampled five times between 25 March and 5 April 2008. A starting point was chosen randomly for each sampling occasion from the list of sites and sampling proceeded in a direction (clockwise or counter-clockwise) around the reservoir that was also chosen randomly. Sampling effort at each individual site consisted of electrofishing for $30 \mathrm{~m}$ along the shoreline in depths $<1.5 \mathrm{~m}$. During sampling, all walleye were collected and measured for total length (TL; $\mathrm{mm}$ ), examined by gently squeezing the abdomen to determine gender and reproductive maturity (Schreck and Moyle 1990) and released alive. Only adult walleye (fish $\geq 250$-mm TL or extruding milt or eggs; Carlander 1945) were included in the model.

\section{Habitat variables}

Abiotic variables were measured at each site for further refinement of the occupancy modeling. Sitespecific covariates (cover type, substrate type, fetch) 
were assumed to remain constant across the spawning season and were thus, only measured once at each site. Cover type (no vegetation, woody shrubs/trees, submerged aquatic vegetation, emergent aquatic vegetation) was visually assessed. Substrate type (silt, sand, gravel, cobble, rock) was either visually assessed in areas of low turbidity or assessed using a substrate sampler made of 102-mm diameter metal pipe. Three values of fetch were calculated using linear measurements for each site in ArcMap 9.3: maximum fetch was calculated as the maximum linear measurement of water for wind to act upon to create waves; northwest fetch was calculated as the maximum linear measurement of water for wind to act upon to create waves from the northwest (the predominant wind direction for this period); and south fetch was calculated as the maximum linear measurement of water to the south of the site (indicative of storm effects on site). Fetch was considered as an additional habitat variable because of its possible influence on dissolved oxygen, dislodgement of eggs during development, and sedimentation and turbidity at spawning sites. Sample-specific covariates (waterquality parameters) were assumed to change between sampling events and were measured $0.5-\mathrm{m}$ below the water's surface at the end of each 30-m sampling transect. Water-quality covariates measured included conductivity $(\mu \mathrm{S} / \mathrm{cm})$, dissolved oxygen $(\mathrm{mg} / \mathrm{L}), \mathrm{pH}$, temperature $\left({ }^{\circ} \mathrm{C}\right)$ and turbidity (NTU).

\section{Walleye eggs}

Sampling for walleye eggs occurred at a randomlyselected 25 of the 50 electrofishing sites in each reservoir to determine presence/absence of spawning. Only 25 of the 50 sites sampled for adults were sampled for eggs due to logistical constraints of deploying and checking egg mats. Egg mats were constructed of tractor disc blades (mean diameter= $43 \mathrm{~cm}$, range $32-57 \mathrm{~cm}$ ) with metal washers welded upright in the center of each disc and covered with outdoor carpeting. Eggs were collected 7-10 days later by rinsing egg mats with water from a boatmounted pump and gently running hands over the carpet to dislodge any attached eggs.

Model selection

Patch occupancy analyses were conducted for each reservoir, separately, using the program PRESENCE
(Hines 2006). Reservoirs were analyzed separately because habitat available for spawning walleye was reservoir specific. Patch occupancy analyses are designed to be used when sites are repeatedly sampled within a short period, such that populations are considered closed (i.e., a site with evidence of occupation is considered occupied throughout the sampling period, and sites cannot become unoccupied once inhabited). Our abundance data was collapsed into presence/absence information, such that only a single individual was needed to declare a site occupied during a single sample. The repeated samples resulted in a detection history for each individual site. For example, if a site is sampled four times and a fish is detected at the first and third sampling attempt, the detection history for that site would be 1010. Detection and occupancy probabilities can be simultaneously estimated from such histories (MacKenzie et al. 2002); the history 1010 provides information that the site is occupied, but the species was not detected during the second and fourth sampling attempt. Thus, the probability of occupancy at this site can then be calculated as

$\psi_{i}=P_{1} *\left(1-P_{2}\right) * P_{3}^{*}\left(1-P_{4}\right)$

where $\psi_{i}$ is the site specific occupancy probability, $P_{j}$ is the probability of detecting the species in the $\mathrm{j}^{\text {th }}$ survey given it is present at the site (MacKenzie et al. 2002). Occupancy analyses use a logit link to incorporate covariates such as habitat and environmental characteristics that may affect detection or occupancy probabilities. Therefore, both detection and occupancy probability can be held constant or vary with specified covariates.

Occupancy analyses assume, in addition to population closure: 1) species are never falsely detected at a site, and 2) detection of species is independent among sites (MacKenzie et al. 2002). Of these assumptions, the closure assumption is the most difficult to meet; it is typically met by making repeated visits to fixed sites within a brief period. The increased effort required to sample each site repeatedly for patch occupancy modeling is often offset by reducing the number of sites at each reservoir (MacKenzie and Royle 2005).

We first developed a list of hypothesized variables that could affect probability of detection for electrofishing: cover type, substrate type, conductivity, 
turbidity and temperature. These covariates were included because they may alter electrofishing efficiency due to a loss of power in vegetation and silt substrate, change in power transfer at different conductivities, difficulty in visually detecting fish in high turbidity or change in fish reaction to electrofishing at different water temperatures (Zalewski and Cowx 1990; Reynolds 1996). We created single-variable models to describe each variable, and all covariate models were compared against the null model, in which detection probability was held constant $(\mathrm{P}, \psi$; no effect of covariates), and a survey-specific $\left(\mathrm{P}_{\mathrm{t}}, \psi\right.$; detection varies only by sampling date) model. In each of these models, occupancy was not allowed to vary so that we could first assess the relative effects on detection probability.

All detection probability models ( $N=7$ per reservoir) were compared using Akaike's Information Criterion, adjusted for small sample size $\left(\mathrm{AIC}_{\mathrm{c}}\right.$; Burnham and Anderson 2002), and tested for overdispersion using the global (over-parameterized) model. Detection probability models with a relative $\mathrm{AIC}_{\mathrm{c}}$ value (i.e., difference between that model's $\mathrm{AIC}_{\mathrm{c}}$ value and the $\mathrm{AIC}_{\mathrm{c}}$ value of the best model; $\Delta \mathrm{AIC}_{\mathrm{c}}$ ) less than 2.0 were considered to have substantial support. The set of top detection probability models was then used to test occupancy probability.

We developed a second set of hypotheses to explain variation in site occupancy of adult walleye during the spawning period: temperature, dissolved oxygen, $\mathrm{pH}$, turbidity, fetch, cover type and substrate type. We constructed models that described these hypotheses, and compared the set of models using the relative $\mathrm{AIC}_{\mathrm{c}}$ score. The combinations of occupancy hypotheses and topranked detection covariates resulted in 31 competing models for Enders Reservoir. These models included detection probability varying as a function of temperature, cover type and substrate type (i.e., the three detection probability models with $\Delta \mathrm{AIC}_{\mathrm{c}}<2$ ) and occupancy parameters. The combinations of occupancy and top detection covariates resulted in 11 competing models for Hugh Butler Lake. These models included detection probability varying as a function of substrate type and occupancy parameters.

We selected a single model as the best model to describe variation in $\mathrm{P}$ and $\psi$, when the top model was $>2$ AICc from all other models. However, we acknowledged uncertainty in model selection when more than one model described variation in
$\mathrm{P}$ and $\psi$ equally well $\left(\Delta \mathrm{AIC}_{\mathrm{c}}<2\right)$. In the latter case, we selected all models with $\Delta \mathrm{AIC}_{\mathrm{c}}<2$ as the final suite of models, and we used model averaging to estimate $\psi$. A model-averaged estimator can reduce bias and uncertainty in model predictions (Burnham and Anderson 2002). The model-specific estimates of $\psi$ were averaged across the suite of best models $\left(\Delta \mathrm{AIC}_{\mathrm{c}}<2\right)$ for each reservoir to obtain an averaged occupancy prediction for each sample site

$\widehat{\bar{\psi}}_{i}=\sum_{i=1}^{R} \hat{\psi}_{i, j} \omega_{j}$

where $\hat{\psi}_{i}$ is the model-averaged estimate of $\psi$ for sample site $i, \hat{\psi}_{i, j}$ is the site-specific occupancy estimate for each model (j), and $\omega_{j}$ is the AICc weight for the $j^{\text {th }}$ model (Burnham and Anderson 2002).

\section{Results}

Most shoreline habitat in Enders Reservoir and Hugh Butler Lake was characterized by silt substrate with small, woody trees (Fig. 1). Sites with rock substrate were found in the lower portion of Enders Reservoir and only on and near the riprap dam in Hugh Butler Lake (Fig. 1). Temperatures were coolest and fetch was generally greater in the downstream portions of each reservoir, whereas dissolved oxygen, conductivity, $\mathrm{pH}$ and turbidity were similar throughout each reservoir.

Adult walleye were captured at $42 \%$ of sampled sites in Enders Reservoir and 16\% of sampled sites in Hugh Butler Lake. Walleye catches were clustered in the lower section of each reservoir. However, some walleye were captured at sites in the middle and upper sections of each reservoir.

The set of best models quantifying detection probability of adult walleye included models in which detection probability varied as a function of temperature, cover type and substrate type in Enders Reservoir, and only as a function of substrate type in Hugh Butler Lake. Detection probability was inversely related to temperature $(\beta \pm \mathrm{SE} ;-1.65 \pm$ 0.38 ) and positively related to the absence of cover $(2.64 \pm 1.23)$ in Enders Reservoir. Detection probability was inversely related to the presence of silt in both reservoirs (-3.32 \pm 0.74 in Enders; $-4.33 \pm 1.3$ in Hugh 
Butler). Detection probability (p) of adult walleye from the best model ranged between 0.001 and 0.82 among sample sites in Enders Reservoir and between 0.03 and 0.18 among sample sites in Hugh Butler Lake.

The set of best occupancy models $(\Delta \mathrm{AICc}<2.0)$ in Enders Reservoir included models in which detection probability varied as a function of cover type and occupancy probability varied as a function of temperature and two measures of fetch: northwest and maximum (Table 1). Occupancy probability was inversely related to temperature $(-1.00 \pm 0.38)$ and positively related to both northwest $(0.0018 \pm 0.0008)$ and maximum fetch $(0.0028 \pm 0.0013$; Fig. 2). Occupancy probability of adult walleye ranged between 0.01 and 0.77 among sampling sites for the best model in Enders Reservoir. Averaged occupancy probabilities in Enders Reservoir were greatest near the riprap dam (Fig. 3).

The set of best occupancy models $(\Delta \mathrm{AICc}<2.0)$ in Hugh Butler Lake included adult walleye occupancy probability varying as a function of the presence of woody cover and substrate type (Table 2). Cover type was reduced to the presence or absence of woody vegetation due to convergence issues with the full cover model. Occupancy probability was positively related to the presence of large substrate $(26.19 \pm$ 395.13) and negatively related to the presence of woody cover $(-35.96 \pm 102.86)$. Occupancy probability of adult walleye ranged between 0.12 and 1.0 among sampling sites for the best model in Hugh Butler Lake. Averaged occupancy probabilities in Hugh Butler Lake were low at all sites, with the exception of the four sites with rock substrate in the lower reservoir (Fig. 3).

Walleye eggs were captured at one site at Enders Reservoir and two sites at Hugh Butler Lake. Eggs were collected only on the riprap dam at Enders Reservoir. Eggs were collected on the riprap dam and on an area of large natural rock substrate adjacent to the dam at Hugh Butler Lake. These sites also had the greatest averaged occupancy probabilities in both reservoirs.

\section{Discussion}

Patch occupancy modeling facilitated quantification of habitat selection by adult walleye in irrigation reservoirs of southwestern Nebraska, while explicitly
Table 1 Occupancy probability models given best detection probability models for adult walleye at Enders Reservoir, Nebraska during spring 2008. Subscripts indicate covariates by which detection probability (p) and $\psi$ vary. Number of parameters is the total number of model estimated parameters (i.e., one intercept parameter for detection and occupancy, one beta parameter for each continuous covariate and one beta parameter for each level of categorical variables). Models with Akaike $\omega<0.01$ are not shown; however the global model with all covariates was included for comparison

\begin{tabular}{|c|c|c|c|c|c|}
\hline Model & $\begin{array}{l}\text { Number of } \\
\text { parameters }\end{array}$ & $\begin{array}{l}-2 \text { log } \\
\text { likelihood }\end{array}$ & $\mathrm{AICc}$ & $\Delta \mathrm{AICc}$ & Akaike $\omega$ \\
\hline $\mathrm{p}_{\text {cover }}, \psi_{\text {temp }}$ & 5 & 181.73 & 193.09 & 0.00 & 0.30 \\
\hline$p_{\text {cover }}, \psi_{\text {NW_fetch }}$ & 5 & 182.92 & 194.28 & 1.19 & 0.16 \\
\hline $\mathrm{p}_{\text {cover }}, \psi_{\text {Max_fetch }}$ & 5 & 183.51 & 194.87 & 1.78 & 0.12 \\
\hline $\mathrm{p}_{\text {temp }}, \psi_{\mathrm{NW} \_ \text {fetch }}$ & 4 & 186.45 & 195.34 & 2.24 & 0.10 \\
\hline $\mathrm{p}_{\text {temp }}, \psi_{\text {temp }}$ & 4 & 188.39 & 197.28 & 4.18 & 0.04 \\
\hline $\mathrm{p}_{\text {cover }}, \psi_{\text {subs }}$ & 8 & 177.82 & 197.33 & 4.24 & 0.04 \\
\hline$p_{\text {subs }}, \psi_{\text {max fetch }}$ & 7 & 180.92 & 197.59 & 4.49 & 0.03 \\
\hline $\mathrm{p}_{\text {temp }}, \psi_{\text {max fetch }}$ & 4 & 188.80 & 197.68 & 4.59 & 0.03 \\
\hline $\mathrm{p}_{\text {subs }}, \psi_{\mathrm{NW} \_ \text {fetch }}$ & 7 & 181.27 & 197.94 & 4.84 & 0.03 \\
\hline $\mathrm{p}_{\text {temp }}, \psi_{\text {subs }}$ & 7 & 181.59 & 198.26 & 5.16 & 0.02 \\
\hline $\mathrm{p}_{\text {temp }}, \psi$ & 3 & 191.86 & 198.39 & 5.29 & 0.02 \\
\hline $\mathrm{p}_{\text {subs }}, \psi_{\text {temp }}$ & 7 & 182.17 & 198.84 & 5.74 & 0.02 \\
\hline $\mathrm{p}_{\text {temp }}, \psi_{\mathrm{pH}}$ & 4 & 190.25 & 199.13 & 6.04 & 0.01 \\
\hline $\mathrm{p}_{\text {temp }}, \psi_{\mathrm{DO}}$ & 4 & 190.38 & 199.27 & 6.17 & 0.01 \\
\hline $\mathrm{p}_{\text {temp }}, \psi_{\mathrm{S} \_ \text {fetch }}$ & 4 & 191.05 & 199.94 & 6.85 & 0.01 \\
\hline $\mathrm{p}_{\text {cover }}, \psi$ & 4 & 191.23 & 200.12 & 7.02 & 0.01 \\
\hline $\mathrm{p}_{\text {subs }}, \psi$ & 6 & 186.42 & 200.38 & 7.28 & 0.01 \\
\hline $\mathrm{p}_{\text {temp }}, \psi_{\text {turb }}$ & 4 & 191.56 & 200.45 & 7.35 & 0.01 \\
\hline Global & 26 & 135.70 & 248.75 & 55.65 & 0.00 \\
\hline
\end{tabular}



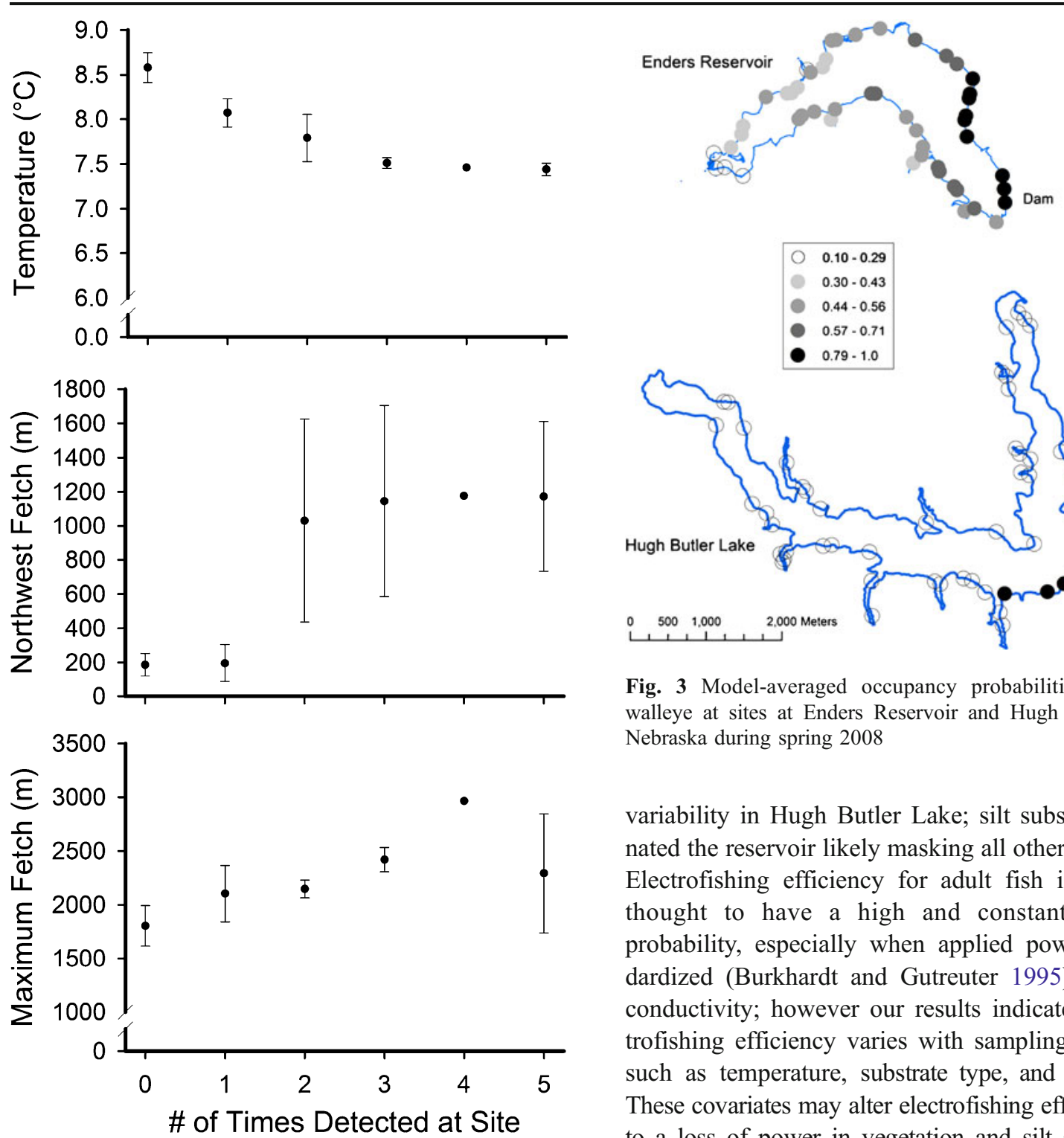

Fig. 2 Mean \pm SE water temperature $\left({ }^{\circ} \mathrm{C}\right.$; top panel), northwest fetch $(\mathrm{m}$; middle panel) and maximum fetch $(\mathrm{m}$; bottom panel) as a function of the number of times walleye occurred at each site at Enders Reservoir, Nebraska during spring 2008. The number of times walleye occurred at each site is used as a surrogate to occupancy probability (i.e., the more times walleye occurred at an individual site, the greater the probability of occupancy). No error bars shown for site $(n=1)$ walleye occupied four times

accounting for variation in detection probability. Detection probability was significantly affected by habitat covariates for adult walleye. The discrepancies between the detection probability models for the two reservoirs are likely caused by the lack of substrate

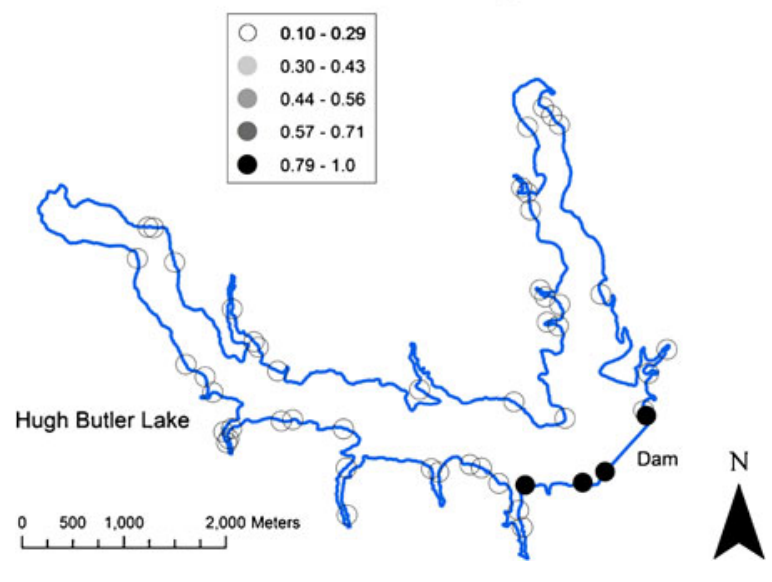

Fig. 3 Model-averaged occupancy probabilities for adult walleye at sites at Enders Reservoir and Hugh Butler Lake, Nebraska during spring 2008

variability in Hugh Butler Lake; silt substrate dominated the reservoir likely masking all other covariates. Electrofishing efficiency for adult fish is generally thought to have a high and constant detection probability, especially when applied power is standardized (Burkhardt and Gutreuter 1995) for water conductivity; however our results indicate that electrofishing efficiency varies with sampling covariates such as temperature, substrate type, and cover type. These covariates may alter electrofishing efficiency due to a loss of power in vegetation and silt substrate or change in fish reaction to electrofishing at different water temperatures (Zalewski and Cowx 1990; Reynolds 1996). With traditional habitat selection methods, managers run the risk of spending money to improve habitat in which detection probability is greatest and not in habitat that is essential to the organism in question.

Walleye in Enders Reservoir selected sites during spawning season that were cooler and had greater fetch (maximum and northwest) than other available sites within the reservoir. The model results lend support to the fetch portion of our a priori hypothesis (i.e., that walleye will select spawning sites that have large substrate and large maximum fetch). For most 
Table 2 Occupancy probability $(\psi)$ models given best detection probability model for adult walleye at Hugh Butler Lake, Nebraska during spring 2008. Subscripts indicate covariates by which detection probability (p) and $\psi$ vary. Number of parameters is the total number of model estimated parameters (i.e., one intercept parameter for detection and occupancy, one beta parameter for each continuous covariate and one beta parameter for each level of categorical variables). Models with Akaike $\omega<0.01$ are not shown; however the global model with all covariates was included for comparison

\begin{tabular}{|c|c|c|c|c|c|}
\hline Model & Number of parameters & -2 log likelihood & $\mathrm{AICc}$ & $\triangle \mathrm{AICc}$ & Akaike $\omega$ \\
\hline $\mathrm{p}_{\text {subs }}, \psi_{\text {woody_cover }}^{\mathrm{a}}$ & 5 & 75.69 & 87.06 & 0.00 & 0.63 \\
\hline $\mathrm{p}_{\text {subs }}, \psi_{\text {subs }}$ & 6 & 75.00 & 88.96 & 1.90 & 0.24 \\
\hline $\mathrm{p}_{\text {subs }}, \psi_{\text {temp }}$ & 5 & 81.75 & 93.12 & 6.06 & 0.03 \\
\hline $\mathrm{p}_{\text {subs }}, \psi_{\mathrm{pH}}$ & 5 & 82.06 & 93.42 & 6.36 & 0.03 \\
\hline$p_{\text {subs }}, \psi_{\mathrm{NW}_{-} \text {fetch }}$ & 5 & 82.29 & 93.65 & 6.60 & 0.02 \\
\hline $\mathrm{p}_{\text {subs }}, \psi_{\mathrm{DO}}$ & 5 & 83.12 & 94.48 & 7.43 & 0.02 \\
\hline$p_{\text {subs }}, \psi_{\text {max_fetch }}$ & 5 & 83.39 & 94.75 & 7.69 & 0.01 \\
\hline $\mathrm{p}_{\text {subs }}, \psi$ & 4 & 86.50 & 95.38 & 8.33 & 0.01 \\
\hline Global & 20 & 49.90 & 118.86 & 31.81 & 0.00 \\
\hline
\end{tabular}

a Reduced to the presence of woody cover due to model convergence issues

sites at Enders Reservoir, the maximum fetch was in the northwest direction, indicating correlation between these two variables. The inverse relationship with walleye presence and temperature seems counterintuitive at first glance. Selecting for spawning sites that would increase incubation time of eggs should lead to greater egg predation and increased chances of desiccation by water-level drawdown in these reservoirs, an evolutionarily negative consequence. However, decreased incubation time (i.e., warmer water temperature) may lead to shorter length at hatch and greater rates of abnormalities (van Eenennaam et al. 2005).

Walleye in Hugh Butler Lake selected sites during spawning season that were free of woody cover (i.e., had no cover present) and had large substrate. These sites were limited to the area near or on the dam at Hugh Butler Lake. These results lend support to the substrate portion of our hypothesis. Although fetch was specified in our hypothesis, it was not present in the best set of models for Hugh Butler Lake likely because of two outlier sites in the northern arm of Hugh Butler Lake that contained walleye and had small fetch values.

Catches of walleye eggs during spawn provide further support for walleye selecting sites on or near the riprap dams for spawning. All walleye eggs captured were located at sites with coarser substrates (natural rock or riprap) on or near the dams. Results from a concurrent study on walleye spawning in
Nebraska indicate that walleye will spawn on added spawning substrate (i.e., cobble) near the dam (Katt et al. 2011). However, the relative importance of adding this cobble near the dam is confounded by other characteristics of the lower portion of the reservoir such as greater fetch, lack of cover and cooler water temperatures. A previous habitat improvement project at Enders Reservoir added large rock perpendicular to the shoreline in areas on the western shore and walleye occupancy probabilities were greater at these sites than at nearby sites (Fig. 3) indicating greater use of these areas than surrounding habitat during walleye spawn.

Our use of patch occupancy analysis added to the knowledge of walleye habitat selection because of the unique study area in which it was used. We identified large rock substrate, lack of woody cover, cooler temperatures, and large fetch as being important for adult walleye spawning site selection. Previous studies have found large rock substrate to be important in reservoirs (Grinstead 1971), tributaries (Kelder and Farrell 2009; Chalupnicki et al. 2010), and natural lakes (Scott 1967; Becker 1983). Large fetch was also important in natural lakes (Becker 1983). However, few walleye were found in areas of flooded vegetation in our study contradictory to the results of Priegel (1970). Our results are also counterintuitive with regard to temperature of spawning sites. Optimal spawning site temperatures of 11$17^{\circ} \mathrm{C}$ (McMahon et al. 1984) are significantly warmer 
than the sites where walleye were spawning in both Enders and Hugh Butler Reservoir. Some of these differences may be attributed to the lack of inflow into these two reservoirs during walleye spawn. If walleye were allowed to run upstream during wet years to spawn in areas of flooded marsh with warmer temperatures, results of this study may be different.

Our results support previous findings that, when available, walleye spawn on large rock (e.g., riprap). Within irrigation reservoirs such as Enders and Hugh Butler, large rock is generally available only at the dam, which results in concentration, perhaps even over-crowding of spawning walleye at the dam. Yearclass strength of walleye is quite variable, with missing year-classes common, in irrigation reservoirs of the Republican River basin in southwestern Nebraska. It is likely that concentration of spawning walleye into a small portion of these reservoirs leads to unfavorable conditions (e.g., increased intraspecific competition and attraction of predators) for egg and larval survival. The addition of riprap in upper portions of irrigation reservoirs would likely disperse spawning walleye, potentially increasing recruitment of walleye and perhaps minimizing variability of year-class strength within reservoirs. In this case, we suggest adopting an adaptive management approach (Halbert 1993) combining research (i.e., further hypotheses of habitat selection) and management goals (i.e., improved habitat and year-class strength of walleye). To test the hypothesis of increased competition and predation due to spawning in a restricted area, we suggest that new riprap be oriented perpendicular to depth contours in a manner that provides submerged riprap at multiple water levels because inter-annual fluctuations in water level are common in irrigation reservoirs.

Fishery managers often take for granted the effectiveness of their sampling gear, both across different habitats and different species. When designing future habitat selection studies, we suggest using patch occupancy modeling to assess both detection probability and occupancy probability simultaneously. This method is widely used in wildlife habitat selection studies and has been slow to catch on in fishery studies. However, the mobility of the species of interest should be considered when designing these studies, as the closure assumption is the most difficult to meet. Highly mobile species are likely to violate this assumption by moving outside of specific sites during the sampling period. Targeting specific species, or species during a particularly immobile season, may be the most appropriate use of this analysis technique in fishery science.

Acknowledgements We thank Chris Lewis and many volunteers for assistance with field work. We also thank Mark Fincel and Mark Pegg for helpful comments on earlier drafts of this manuscript. This project was funded by Federal Aid in Sport Fish Restoration, project F-174-R, administered by the Nebraska Game and Parks Commission. LAP's contribution was supported by Hatch Act funds through the University of Nebraska Agricultural Research Division, Lincoln, Nebraska. Reference to trade names does not imply endorsement by the authors or any U.S. Government. The Nebraska Cooperative Fish and Wildlife Research Unit is jointly supported by a cooperative agreement among the U.S. Geological Survey, the Nebraska Game and Parks Commission, the University of Nebraska, the U.S. Fish and Wildlife Service, and the Wildlife Management Institute.

\section{References}

Becker GC (1983) Fishes of Wisconsin. University of Wisconsin Press, Madison, Wisconsin

Burdick SM, Hendrixson HA, VanderKooi SP (2008) Age-0 Lost River sucker and shortnose sucker nearshore habitat use in Upper Klamath Lake, Oregon: a patch occupancy approach. Trans Am Fish Soc 137:417-430

Burkhardt RW, Gutreuter S (1995) Improving electrofishing catch consistency by standardizing power. N Am J Fish Mngt 15:375-381

Burnham KP, Anderson DR (2002) Model selection and multimodel inference: a practical information-theoretic approach, 2nd edn. Springer, New York

Carlander KD (1945) Age, growth, sexual maturity, and population fluctuations of the yellow pike-perch, Stizostedion vitreum vitreum (Mitchill), with reference to the commercial fisheries, Lake of the Woods, Minnesota. Trans Am Fish Soc 73:90-107

Chalupnicki MA, Johnson JH, McKenna JE Jr, Dittman DE (2010) Habitat selection and spawning success of walleyes in a tributary to Owasco Lake, New York. N Am J Fish Mngt 30:170-178

Gipson RD, Hubert WA (1993) Spawning-site selection by kokanee along the shoreline of Flaming Gorge Reservoir, Wyoming-Utah. N Am J Fish Mngt 13:475-482

Gosch NJC, Phelps QE, Willis DW (2006) Habitat characteristics at bluegill spawning colonies in a South Dakota glacial lake. Ecol Freshw Fish 15:464-469

Grinstead BG (1971) Reproduction and some aspects of the early life history of walleye, Stizostedion vitreum (Mitchill) in Canton Reservoir, Oklahoma. In: Hall GE (ed), Reservoir fisheries and limnology. Am Fish Soc Spec Pub 8, Washington, D.C. pp. 41-51 
Groen CL, Schroeder TA (1978) Effects of water level management on walleye and other coolwater fishes in Kansas reservoirs. Am Fish Soc Spec Publ 11:278-283

Gu W, Swihart RK (2004) Absent or undetected? Effects of non-detection of species occurrence on wildlife-habitat models. Biol Conserv 116:195-203

Halbert CL (1993) How adaptive is adaptive management? Implementing adaptive management in Washington State and British Columbia. Rev Fish Sci 1:261-283

Hayer CA, Irwin ER (2008) Influence of gravel mining and other factors on detection probabilities of coastal plain fishes in the Mobile River basin, Alabama. Trans Am Fish Soc 137:1606-1620

Hines JE (2006) PRESENCE2 - Software to estimate patch occupancy and related parameters. USGS-PWRC. http:// www.mbr-pwrc.usgs.gov/software/presence.html

Johnson FH (1961) Walleye egg survival during incubation on several types of bottom in Lake Winnibigoshish, Minnesota, and connecting waters. Trans Am Fish Soc 90:312-322

Katt JD, Peterson BC, Koupal KD, Schoenebeck CW, Hoback WW (2011) Changes in relative abundance of adult walleye and egg density following the addition of walleye spawning habitat in a midwest irrigation reservoir. J Fresh Ecol 26:51-58

Kelder BF, Farrell JM (2009) A spatially explicit model to predict walleye spawning in an Eastern Lake Ontario tributary. N Am J Fish Mngt 29:1686-1697

MacKenzie DI, Royle JA (2005) Designing occupancy studies: general advice and allocating survey effort. J App Ecol 42:1105-1114

MacKenzie DI, Nichols JD, Lachman GB, Droege S, Royle JA, Langtimm CA (2002) Estimating site occupancy rates when detection probabilities are less than one. Ecology $83: 2248-2255$

Martin DR (2008) Habitat selection by spawning walleye and white bass in irrigation reservoirs of the Republican River Basin, Nebraska. Thesis, University of Nebraska-Lincoln
McMahon TE, Terrell JW, Nelson PC (1984) Habitat suitability information: walleye. Fish and Wildlife Service, U.S. Department of the Interior, FWS/OBS-82/10.56, Washington, D.C.

Pflieger WL (1997) The fishes of Missouri, revisedth edn. Missouri Department of Conservation, Jefferson City

Priegel GR (1970) Reproduction and early life history of the walleye in the Lake Winnebago region. Wisconsin Department of Natural Resources Technical Bulletin 45, Madison

Quist MC, Guy CS, Bernot RJ, Stephen JL (2004) Factors related to growth and survival of larval walleyes: implications for recruitment in a southern Great Plains reservoir. Fish Res 67:215-225

Reynolds JB (1996) Electrofishing. In: Murphy BR, Willis DW (eds) Fisheries techniques, 2nd edn. American Fisheries Society, Bethesda, Maryland, pp 221-253

Schoenebeck CW, Hansen MJ (2005) Electrofishing catchability of walleye, largemouth bass, smallmouth bass, northern pike, and muskellunge in Wisconsin Lakes. N Am J Fish Mngt 25:1341-1352

Schreck CB, Moyle PB (1990) Methods for fish biology. American Fisheries Society, Bethesda, Maryland

Scott WB (1967) Freshwater fishes of eastern Canada. University of Toronto Press, Toronto, Ontario

Tyre AJ, Tenhumberg B, Field SA, Niejalke D, Parris K, Possingham HP (2003) Improving precision and reducing bias in biological surveys: estimating false-negative error rates. Ecol App 13:1790-1801

Van Eenennaam JP, Linares-Casenave J, Deng X, Doroshov SI (2005) Effect of incubation temperature on green sturgeon embryos, Acipenser medirostris. Environ Biol Fish 72:145-154

Zalewski M, Cowx IG (1990) Factors affecting the efficiency of electric fishing. In: Cowx IG, Lamarque P (eds) Fishing with electricity: applications in freshwater fisheries management. Fishing News Books, Oxford, pp 89-111 